\title{
A PROSPECTIVE STUDY ON PREVALENCE OF EPILEPSY DISORDERS AND DRUG UTILIZATION PATTERN
}

\author{
JYOTI UPADHYAY ${ }^{1 *}$, GAURAV UPADHYAY ${ }^{2}$, AMITA JOSHI RANA ${ }^{1}$
}

${ }^{1}$ Department of Pharmaceutical Sciences, Kumaun University Nainital, Nainital, Uttarakhand, India. ${ }^{2}$ K.N Modi Institute of Pharmaceutical Education and Research, Modinagar, Uttar Pradesh, India. Email: jyotsna_pharma07@yahoo.co.in

Received: 09 October 2016, Revised and Accepted: 30 November 2016

\section{ABSTRACT}

Objective: Epilepsy is the second most common neurologic disorder after stroke. The study was undertaken to determine the prevalence of epilepsy disorders and drug utilization pattern in a patient population of Dehradun. This study was conducted in a private health clinic.

Methods: A questionnaire was prepared that includes many practical questions regarding epilepsy seizure type, medication prescribed, their health status, and compliance. A total of 200 cases of epilepsy were reported.

Results: The study showed the prevalence of epilepsy disorders which was most common among males (65\%) as compared to females (35\%). 44\% of epilepsy disorders were found prevalent among the age group between 30 and 40 years. The most common type of epilepsy disorder is primary generalized seizure (62\%) followed by partial seizures (23\%), focal disorder (6\%), grand mal cortical focal epilepsy (5\%), typical seizures (3.5\%), refractory seizures $(3 \%)$, and others $(2.5 \%)$.

Conclusion: Epilepsy is one of the most serious neurological disorders in terms of both prevalence and cumulative incidence. Good education and counseling is required for coping up the challenges of this condition as well for improving patient compliance. For decreasing the chances of adverse effects and avoiding drug interactions monotherapy is important. Health-care providers and patients can together formulate a better therapeutic plan for achieving a seizure-free status without adverse effects.

Keywords: Seizures, Antiepileptic drugs, Compliance.

(C) 2017 The Authors. Published by Innovare Academic Sciences Pvt Ltd. This is an open access article under the CC BY license (http://creativecommons. org/licenses/by/4. 0/) DOI: http://dx.doi.org/10.22159/ajpcr.2017.v10i3.15605

\section{INTRODUCTION}

About $10 \%$ of people will have one seizure in their lifetime and about a third of them will go on to develop epilepsy [1,2]. It is a disorder that can occur in all mammalian species, probably more frequently as brain has become more complex and also remarkably uniformly distributed around the world. There are no racial, geographical or social class boundaries, it occurs in both sexes, at all ages, especially in childhood, adolescence and increasingly in ageing populations $[3,4]$. About $10 \%$ epileptic seizures may cause convulsions if the motor cortex is involved. The seizures may involve visual, auditory, or olfactory hallucinations if the parietal and occipital cortex plays a role.

Although drug therapy is the most widely effective mode for the treatment of epilepsy, it is not hundred percent effective in all patients. For example, it is frequently hindered by poor patient adherence, and often it is complicated by drug interactions. However, seizures can be controlled completely in approximately $50 \%$ of epileptic patients and a meaningful improvement is achieved in at least half of the remaining patients. An epileptic seizure is a transient paroxysm of uncontrolled discharges of neurons causing an event that is discernible by the person experiencing the seizure and/or by an observer. The tendency to have recurrent attacks is known as epilepsy; by definition a single attack does not constitute epilepsy. A patient with epilepsy will show recurrent epileptic seizures that occur unexpectedly and stop spontaneously [5,6].

Epilepsy has a focal origin in the brain. It manifests from the site of the focus, regions into which the discharges spread. Most of the cases are primary (idiopathic), some may be secondary to trauma/surgery on head, intracranial tumor, tuberculoma, cysticercosis, cerebral ischemia, etc. Epilepsies have been classified variously: Major types are given in Table 1 [4].

\section{Treatment of epilepsies}

Antiepileptic drugs suppress seizures but do not cure the disorder; the disease may fadeout though after years of successful control. Control and prevention of all seizure activity is the aim of antiepileptic drugs at an acceptable level of side effects. Selection of an anticonvulsant medication depends on an accurate diagnosis of the epileptic syndrome. Some anticonvulsants (e.g., lamotrigine, topiramate, and valproic acid) have multiple mechanisms of action and some (e.g., phenytoin and carbamazepine) have only one known mechanism of action, anticonvulsant agents can be divided into large groups based on their mechanisms are given in Table 2 [6].

\section{METHODS}

The study has been conducted to observe the prevalence and drug utilization pattern in epileptic patients in a private health clinic. The main objectives include investigation of the prevalence of epilepsy disorders, types, determination of gender wise and age wise distribution of epileptic patients and observation of their drug utilization pattern. This study included 200 subjects, after informing them about the purpose of the study and prior consent. A questionnaire was prepared that includes many practical questions regarding disease condition, medication prescribed, health status, and patient compliance. Table 3 shows the questions which were asked from the epileptic patient.

\section{RESULTS}

This study included 200 epileptic patients among which 130 (65\%) were males and 70 (35\%) were females (Fig. 1). The age wise 
Table 1: Classification of major types of epilepsy [4]

\begin{tabular}{|c|c|}
\hline Types & Description \\
\hline \multicolumn{2}{|l|}{ Generalized seizures } \\
\hline GTCS, major epilepsy, grand mal epilepsy & $\begin{array}{l}\text { It is the most common disorder, lasts } 1-2 \text { min. Aura-cry- unconsciousness-tonic } \\
\text { spasm of all body muscles- clonic jerking followed by prolonged sleep and } \\
\text { depression of all CNS functions }\end{array}$ \\
\hline \multirow[t]{2}{*}{ Absence seizures (minor epilepsy, petit mal) } & It last about $1 / 2$ minute, prevalent in children \\
\hline & $\begin{array}{l}\text { Momentary loss of consciousness, patient apparently freezes and stares in one } \\
\text { direction, no muscular component or little bilateral jerking. EEG shows characteristic } \\
3 \text { cycles per second spike and wave pattern }\end{array}$ \\
\hline Atonic seizures (Akinetic epilepsy) & $\begin{array}{l}\text { Unconsciousness with relaxation of all muscles due to excessive inhibitory } \\
\text { discharges patient may fall }\end{array}$ \\
\hline Myoclonic seizure & Shock like momentary contraction of muscles of limb or the whole body \\
\hline Infantile spasms (hypsarrhythmia) & $\begin{array}{l}\text { Seen in infants. Probably not a form of epilepsy. Intermittent muscles spasm and } \\
\text { progressive mental deterioration. Diffuse changes in the inter seizure EEG are noted }\end{array}$ \\
\hline \multicolumn{2}{|r|}{ P = } \\
\hline SPS, cortical focal epilepsy & $\begin{array}{l}\text { Often secondary, last } 1 / 2-1 \text { minute. Convulsion are confined to a group of muscles } \\
\text { or localized sensory disturbance depending on the area of cortex involved in the } \\
\text { seizure, without loss of consciousness }\end{array}$ \\
\hline CPS, temporal lobe epilepsy, psychomotor & $\begin{array}{l}\text { Attacks of bizarre and confused behavior and purposeless movements, emotional } \\
\text { changes lasting 1-2 minutes along with impairment of consciousness. An aura often } \\
\text { proceeds. The seizure focus is located in the temporal lobe }\end{array}$ \\
\hline $\begin{array}{l}\text { Simple partial or complex partial seizures secondarily } \\
\text { generalized }\end{array}$ & $\begin{array}{l}\text { The partial seizure occurs first and evolves into generalized tonic-clonic seizures with } \\
\text { loss of consciousness }\end{array}$ \\
\hline \multicolumn{2}{|c|}{ GTCS: Generalized tonic-clonic seizures, SPS: Simple partial seizure, CPS: Complex partial seizures } \\
\hline Mechanism of action & Drugs \\
\hline Blockers of repetitive activation of the sodium channel & Phenytoin, carbamazepine, oxcarbazepine, lamotrigine, topiramate \\
\hline Enhancer of slow inactivation of the sodium channel & Lacosamide, rufinamide \\
\hline GABA-A receptor enhancers & Phenobarbital, benzodiazepines, clobazam \\
\hline NMDA receptor blockers & Felbamate \\
\hline AMPA receptor blockers & Perampanel, topiramate \\
\hline H-current modulators & Gabapentin, lamotrigine \\
\hline Blockers of unique binding sites & Gabapentin, levetiracetam \\
\hline Carbonic anhydrase inhibitors & Topiramate, zonisamide \\
\hline Neuronal potassium channel (KCNQ [Kv7]) opener & Ezogabine \\
\hline
\end{tabular}

GABA: Gamma-aminobutyric acid

Table 3: Questionnaire

Questions were asked regarding

Types of epilepsy disorders

Medication prescribed

Patient compliance for medication

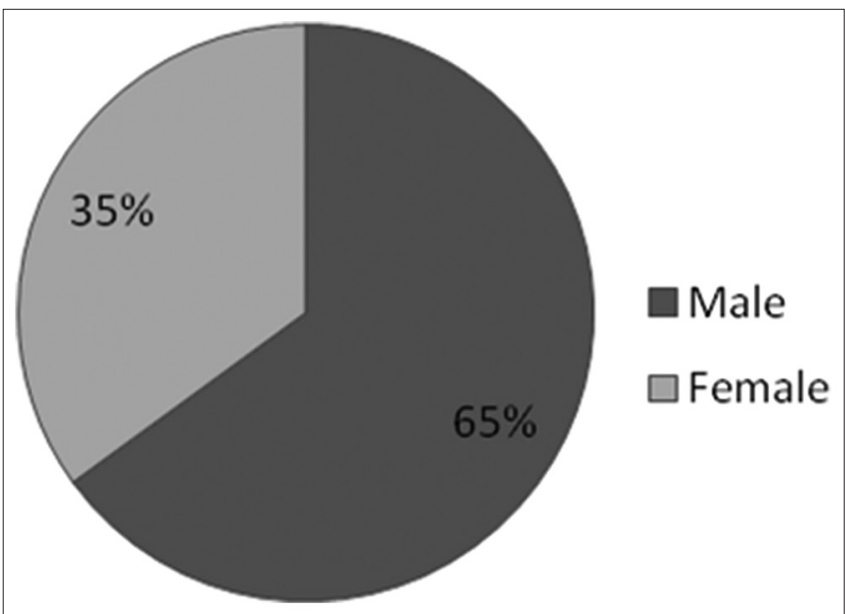

Fig. 1: Gender wise distribution of epileptic patients distribution of epilepsy disorders showed that $44 \%$ of disorders were prevalent among age group between 30 and 40 years (Fig. 2). This study highlighted that primary generalized seizures $(62 \%)$ were most common among the concerned epileptic patients (Fig. 3).

Table 4 shows the type of epilepsy disorders among male and female patients and their total percentage of prevalence. Grand mal epilepsy $(66 \%)$ is the major type of generalized seizures prevalent among male patients. Table 5 shows the antiepileptic drugs given for a particular type of epilepsy disorders. Benzodiazepine, phenytoin, and valproate are the most commonly prescribed drugs categories. It was also found that some other drugs were prescribed such as Aciloc and multivitamins, along with antiepileptic drugs. This study also revealed that $04 \%$ of patients in the age group $60-70$ years were noncompliant for their medication due to given reasons such as faces difficulty in swallowing, forget to take medicines, and poor economic status.

\section{DISCUSSION AND CONCLUSION}

The goal of treatment is to achieve a seizure-free status without adverse effects. Monotherapy is important, because it decreases the likelihood of adverse effects and avoids drug interactions. Adaption of treatment decisions to the characteristics of the individual is the key to optimum epilepsy management. Antiepileptic drugs monotherapy is indicated after two seizures, but in high-risk patients initiation of treatment after one seizure might be justifiable. Dose titration and 
Table 4: Epilepsy types and their percentage of prevalence among male and female

\begin{tabular}{|c|c|c|c|c|}
\hline Type & Male (n=130) & Female $(n=70)$ & Total $(n=200)$ & Percentage $(n=200)$ \\
\hline Primarily generalized seizures & 90 & 34 & 124 & 62 \\
\hline Grand mal epilepsy & 66 & 22 & 88 & 44 \\
\hline Status epilepticus & 08 & 03 & 11 & 5.5 \\
\hline Infantile spasm & 04 & 02 & 06 & 3 \\
\hline Myoclonic seizures & 04 & 03 & 07 & 3.5 \\
\hline Atonic seizures & 02 & - & 02 & 1 \\
\hline Petit mal epilepsy & 06 & 04 & 10 & 5 \\
\hline Partial seizures & 14 & 12 & 26 & 13 \\
\hline CPS & 14 & 04 & 18 & 9 \\
\hline SPS & - & 08 & 08 & 4 \\
\hline Focal disorder & 10 & 02 & 12 & 6 \\
\hline Refractory seizures & - & 06 & 06 & 3 \\
\hline Grand mal cortical focal epilepsy & 08 & 02 & 10 & 5 \\
\hline Cebrile convulsions & - & 05 & 05 & 2.5 \\
\hline General dilation of ventricles & 05 & - & 05 & 2.5 \\
\hline Head injury & - & 05 & 05 & 2.5 \\
\hline Typical seizure & 03 & 04 & 07 & 3.5 \\
\hline
\end{tabular}

CPS: Complex partial seizures, SPS: Simple partial seizures

Table 5: Drug treatment given to epileptic patients

\begin{tabular}{|c|c|c|}
\hline Disease & Antiepileptic drugs & Other drugs given \\
\hline Status epilepticus & $\begin{array}{l}\text { Phenytoin (phenytal), valproate (valvorin), carbin SR (carbamazepine) } \\
\text { cecozam (diazepam) }\end{array}$ & - \\
\hline GTCS & $\begin{array}{l}\text { Carbamazepine - SR, secozam (diazepam), clobazam (clonazepam), } \\
\text { calmpose (diazepam), serpex (oxazepam) }\end{array}$ & Aciloc multivitamins \\
\hline Refractory seizures & Clobazam, secozam & - \\
\hline Petit mal epilepsy & Encorate (Sod. valproate) & Syrup i-vit B-complex \\
\hline $\begin{array}{l}\text { Grand mal, cortical focal, and psychomotor } \\
\text { epilepsy }\end{array}$ & Phenytoin-SR (fentain) phenobarbitone & Syrup i-vit \\
\hline Infantile spasm & Clonazepam & \\
\hline Cortical focal seizures & Phenytoin (phenytoin) diazepam (secozam) & Aciloc \\
\hline Febrile convulsions & Diazepam (calmpose) & \\
\hline Atonic seizures & Clonazepam secozam & Aciloc \\
\hline Head injury & Divalproex, carbin-SR, tegretol, secozam & - \\
\hline Typical seizure & Clonazepam, secozam & Syrup i-vit \\
\hline Complex seizure & Carbital, phenytoin & Syrup i-vit Aciloc \\
\hline Grand mal epilepsy & Divalproex, secozam, libralex & Aciloc \\
\hline
\end{tabular}

GTCS: Generalized tonic clonic seizures

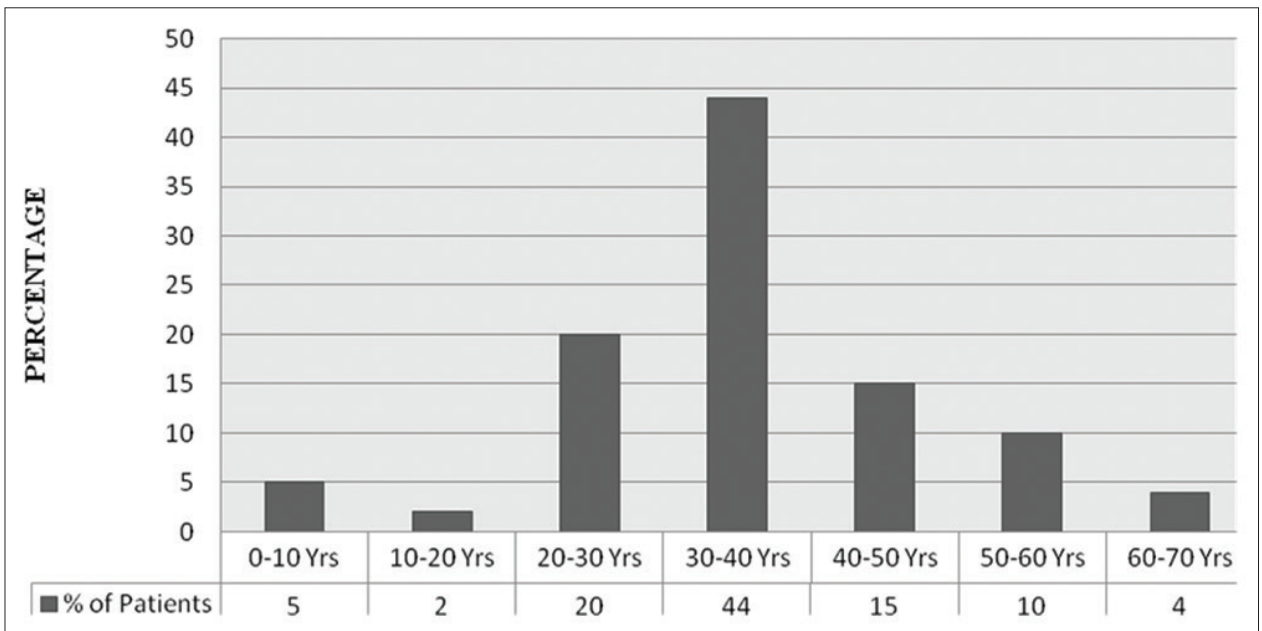

Fig. 2: Age wise distribution of epileptic patients

dosing regimens also need to be carefully individualized. Combination therapy can be beneficial in patients who did not respond to two or three sequential monotherapy, although in some cases earlier institution of polytherapy might be justified. The clinical signs and symptoms of seizures depend on the location of the epileptic discharges in the cerebral cortex and the extent and pattern of the propagation of the epileptic discharge in the brain. A key feature of epileptic seizures is their stereotypic nature. 


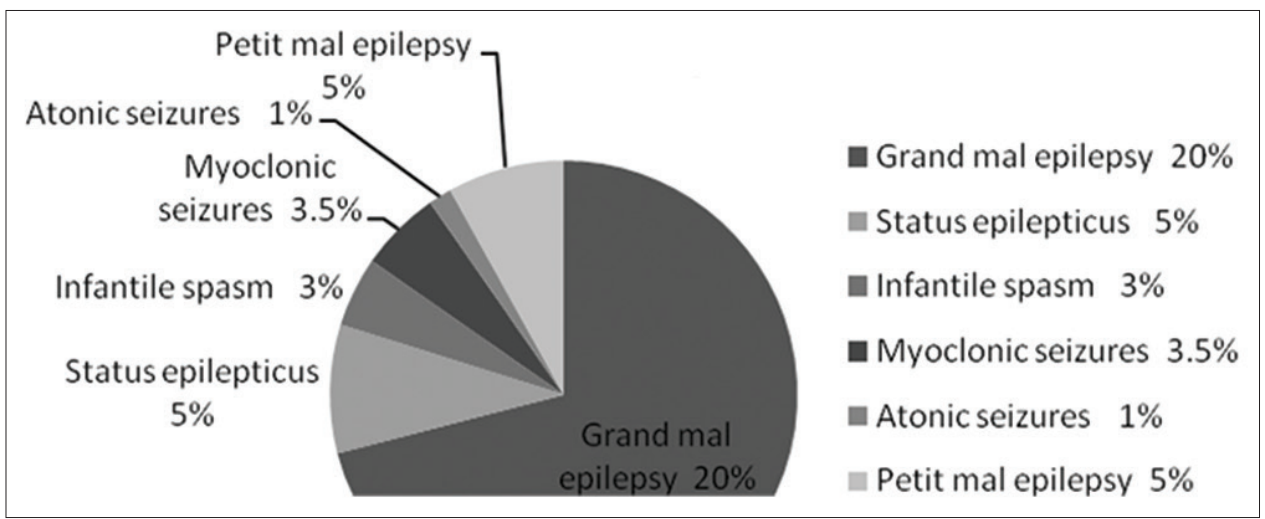

Fig. 3: Prevalence of primary generalized seizure

General principles for the symptomatic treatment of seizures with antiepileptic drugs:

- Choice of drugs and dose is according to the seizure type and need of individual patient. Early initiation of treatment, as each seizure episode increases the propensity to further attacks.

- Start with a single drug, preferably at low dose-gradually increase dose till full control of seizures or side effects appear. If all reasonable monotherapy fails, use combinations.

- Therapy should be as simple as possible. A seizure diary should be maintained.

- When women on antiepileptic therapy conceive, antiepileptic drugs should not be stopped. Discontinuation of therapy carries high-risk of status epilepticus. To avoid the chances of birth defects, an attempt to reduce the dose of drugs should be cautiously made.

Apart from these general principles of treatment, we concluded that the choice of antiepileptic drugs is primarily based on efficacy and effectiveness for the individual's seizure type, but other patient-specific factors need to be considered which includes age, sex, childbearing potential, comorbidities, concomitant medications, and patient compliance [7]. The patient may discontinue the drug if they achieve seizure control after at least 2-4 years of seizure freedom and also after careful assessment of potential benefits versus the risk of relapse and related implications.

\section{REFERENCES}

1. Epilepsy Foundation. Epilepsy and Seizure Statistics. Available from: http://www.epilepsyfoundation.org/about/statistics.cfm. [Last accessed on 2010 Dec 31]

2. Hesdorffer DC, Logroscino G, Benn EK, Katri N, Cascino G, Hauser WA. Estimating risk for developing epilepsy: A populationbased study in Rochester, Minnesota. Neurology 2011;76(1):23-7.

3. Kale R. Bringing epilepsy out of the shadows. BMJ 1997;315(7099):2-3.

4. Tripathi KD. Essentials of Medical Pharmacology. $6^{\text {th }}$ ed. New Delhi: Jaypee Publication; 2008. p. 401.

5. Walker R, Edwards C. Clinical Pharmacy and Therapeutics. Philadelphia, PA: Lippincott Williams and Wilkins; 2003. p. 127-39, 447.

6. Howland RD, Mycek MJ. Lippincott's Illustrated Reviews: Pharmacology. $3^{\text {rd }}$ ed. Philadelphia, PA: Lippincott Williams and Wilkins; 2006. p. 169

7. Perucca E, Tomson T. The pharmacological treatment of epilepsy in adults. Lancet Neurol 2011;10(5):446-56.

8. International League against Epilepsy/International Bureau for Epilepsy/World Health Organization Global Campaign against Epilepsy. Epilepsy in the WHO European Region. 2010. Available from: http://www.ibe-epilepsy.org/downloads/EURO $\% 20$ Report $\% 20$ 160510.pdf. [Last accessed on 2010 Dec 31].

9. Tomson T, Beghi E, Sundqvist A, Johannessen SI. Medical risks in epilepsy: A review with focus on physical injuries, mortality, traffic accidents and their prevention. Epilepsy Res 2004;60(1):1-16.

10. The Lancet Neurology. Epilepsy must become a higher priority in Europe. Lancet Neurol 2010;9(10):941. 